\title{
MENGENALI BAHAN TAMBAHAN PANGAN BERBAHAYA : ULASAN
}

\section{IDENTIFYING HAZARDOUS MATERIALS FOR FOOD ADDITIVE: A REVIEW}

\author{
Jatmiko Wahyudi \\ Badan Perencaan Pembangunan Daerah Kabupaten Pati \\ Email: jatmiko_tkuns@yahoo.com
}

\begin{abstract}
Several studies founded the usage of hazardous materials for food additives in many parts of Indonesia. Stakeholders especially The Government already implemented policies to against the abuse of hazardous food additives like the enactment of food regulations and food safety promotions. Many factors cause many people still using and distributing hazardous food additives (e.g. economic factors, knowledge and law enforcement). This paper provides an overview of types hazardous food additives and the negative impacts of consuming the additives on health emphasizing in the most popular of hazardous food additives namely formalin, borax and rhodamine B. In general, consuming the additives causes long-term health problems like cancer. However, consuming the additives in high dosage will make the consumers experiencing chronic poisoning and even causing death. Campaigns regarding food safety followed by law enforcement are very important actions to be done to eliminate the abuse of hazardous food additives.
\end{abstract}

Keywords: hazardous food additive, borax, formalin, rhodamine $B$

\section{ABSTRAK}

Beberapa studi menunjukkan banyaknya penggunaan bahan yang berbahaya dan dilarang untuk digunakan sebagai bahan tambahan pangan. Pihak terkait khususnya pemerintah telah mengimplementasikan kebijakan untuk menekan penyalahgunaan BTP antara lain dengan pemberlakuan peraturan dan sosialisasi mengenai BTP. Beberapa faktor menjadi penyebab masih maraknya penggunaan BTP berbahaya antara lain faktor ekonomi, pengetahuan dan penegakan hukum. Ulasan ini akan memaparkan mengenai jenis BTP berbahaya yang sering digunakan dan dampak yang ditimbulkan akibat mengkonsumsi BTP tersebut bagi kesehatan dengan menekankan pada 3 jenis bahan terlarang yang paling sering digunakan sebagai BTP yaitu formalin, boraks dan Rhodamin B. Secara umum, mengkonsumsi BTP berbahaya akan memberikan dampak buruk bagi kesehatan dalam jangka panjang misalnya kanker. Namun, konsumsi BTP berbahaya dengan dosis yang tinggi dapat menyebabkan efek negatif langsung pada kesehatan misalnya keracunan bahkan kematian. Sosialisasi diikuti dengan penegakan hukum perlu terus dilakukan untuk mengatasi penyalahgunaan BTP berbahaya.

Kata kunci : bahan tambahan pangan, boraks, formalin, rhodamin B 


\section{PENDAHULUAN}

Dalam Undang-Undang Nomor 18 Tahun 2012 tentang pangan dinyatakan bahwa pemerintah berkewajiban untuk menjamin terwujudnya penyelenggaraan keamanan pangan yang salah satunya dilaksanakan melalui pengaturan penggunaan bahan tambahan pangan (BTP) untuk menjaga pangan yang dikonsumsi masyarakat tetap aman dan higienis. Menurut Peraturan Pemerintah Nomor 28 tahun 2004, yang dimaksud bahan tambahan pangan (BTP) adalah bahan yang ditambahkan ke dalam makanan untuk mempengaruhi sifat atau bentuk pangan atau produk makanan.

Penambahan zat-zat tertentu ke dalam makanan sudah dikenal sejak ratusan tahun yang lalu oleh manusia. Sebagai contoh, masyarakat Mesir kuno menggunakan garam dan rempah-rempah untuk mengawetkan pangan. Menurut Saparinto \& Hidayati (2006), tujuan penambahan BTP secara umum adalah untuk meningkatkan nilai gizi makanan, memperbaiki nilai estetika dan sensori makanan dan memperpanjang umur simpan (shelf life) makanan. Berdasarkan Peraturan Menteri Kesehatan (Permenkes) Nomor 033 Tahun 2012 tentang bahan tambahan pangan, terdapat 27 golongan BTP yang digunakan dalam pangan (Tabel 1).

Berdasarkan Permenkes Nomor 033 Tahun 2012, BTP dibedakan menjadi BTP yang diizinkan dan BTP yang dilarang/berbahaya untuk digunakan. Untuk BTP yang diizinkan, penggunaannya harus diberikan dalam batasan dimana konsumen tidak menjadi keracunan dengan mengkonsumsi tambahan zat tersebut yang dikenal dengan istilah ambang penggunaan. Sementara untuk kategori BTP yang dilarang, penggunaan dengan dosis sekecil apapun tetap tidak diperbolehkan.

Beberapa penelitian menunjukkan masih masifnya penggunaan BTP berbahaya pada berbagai jenis makanan di beberapa daerah di Indonesia. Studistudi tersebut antara lain dilakukan oleh Suntaka dkk (2015) tentang penggunaan formalin dan boraks pada pembuatan bakso di Kota Bitung; Lestari (2009), tentang penggunaan boraks pada pembuatan kerupuk gendar di Kabupaten Demak; dan Matondang dkk (2015) tentang penggunaan formalin pada ikan asin di Kota Bandung. Dalam studi literaturnya, Matondang dkk (2015) bahkan menemukan bahwa penggunaan formalin pada ikan tidak hanya terdeteksi pada ikan yang dijual di pasar-pasar tradisional namun juga ditemukan pada ikan yang dijual di pasar-pasar modern.

Salah satu golongan pangan yang rentan terkontaminasi BTP berbahaya adalah golongan pangan jajanan anak sekolah (PJAS). Dari pengujian sampel jajanan anak sekolah di 538 Sekolah Dasar di 26 kota di Indonesia, 45\% sampel jajanan dinyatakan tidak memenuhi syarat keamanan pangan karena terdeteksi mengandung cemaran mikroba dan BTP yang dilarang (Gartini, 2009). Masih banyaknya masyarakat terutama para pedagang atau pengolah pangan menggunakan BTP berbahaya antara lain disebabkan bahan tersebut harganya murah, lebih efektif dan efisien bila digunakan, mudah digunakan dan 
didapatkan, rendahnya kesadaran masyarakat tentang bahaya zat tersebut serta lemahnya pengawasan dan penegakan hukum dari aparat terkait (Nurkholidah dkk, 2012).

$$
\text { Sebagai contoh adalah }
$$

keberadaaan formalin yang masih sering digunakan sebagai pengawet pangan di masyarakat. Dibandingkan dengan bahan pengawet pangan lain seperti asam benzoat, natrium sorbat atau bahkan garam, formalin memiliki harga yang relatif lebih murah, memiliki efek pengawetan lebih cepat dan kuat meskipun digunakan dalam jumlah/dosis yang lebih kecil. Formalin lebih mudah digunakan karena berbentuk larutan sehingga hanya perlu diencerkan dan langsung bisa dipakai. Selain itu, formalin sangat mudah dibeli di tokotoko bahan kimia disebabkan lemahnya pengawasan dari instansi terkait.

Tabel 1.

Golongan BTP yang digunakan dalam pangan

\begin{tabular}{|c|c|c|}
\hline No & Golongan BTP & Contoh senyawa \\
\hline 1. & Antibuih & Kalsium alginat, Mono dan digliserida asam lemak \\
\hline 2. & Antikempal & Kalsium karbonat, Trikalsium fosfat, Natrium karbonat \\
\hline 3. & Antioksidan & Asam/Natrium/Kalsium/Kalium askorbat \\
\hline 4. & Bahan Pengkarbonasi & Karbon dioksida \\
\hline 5. & Garam Pengemulsi & Natrium dihidrogen sitrat, Dinatrium fosfat \\
\hline 6. & Gas Untuk Kemasan & Karbon dioksida, Nitrogen \\
\hline 7. & Humektan & Natrium/Kalium laktat \\
\hline 8. & Pelapis & Malam, Lilin karnauba, Lilin mikrokristalin \\
\hline 9. & Pemanis & Sorbitol, Silitol, Sakarin, Aspartam \\
\hline 10. & Pembawa & Trietil sitrat, Propilen glikol, Polietilen glikol \\
\hline 11. & Pembentuk Gel & Asam/Natrium/Kalsium/Kalium alginat, Agar-agar \\
\hline 12. & Pembuih & Selulosa mikrokristalin, Etil metil selulosa \\
\hline 13. & Pengatur Keasaman & Asam/Natrium/Kalsium asetat \\
\hline 14. & Pengawet & Asam/Natrium/Kalsium/Kalium benzoat \\
\hline 15. & Pengembang & Dekstrin, Pati asetat, Natrium karbonat \\
\hline 16. & Pengemulsi & Lesitin, Agar-agar, Karagen \\
\hline 17. & Pengental & Asam/Natrium/Kalsium/Kalium alginat, Kalsium asetat \\
\hline 18. & Pengeras & Kalsium laktat, Trikalsium sitrat, Kalium klorida \\
\hline 19. & Penguat rasa & Monosodium L-glutamate ( $M S G$ ), Asam guanilat dan garamnya \\
\hline 20 & Peningkat volume & Natrium laktat, Agar-agar, Karagen \\
\hline 21. & Penstabil & Lesitin, Kalsium karbonat/asetat/laktat \\
\hline 22. & Peretensi Warna & Magnesium karbonat, Magnesium hidroksida \\
\hline 23. & Perisa & rempah-rempah, paprika oleoresin, bubuk keju, ekstrak ragi \\
\hline 24. & Perlakuan Tepung & Amonium klorida, Kalsium sulfat, Kalsium oksida \\
\hline 25. & Pewarna & Kurkumin, Antosianin, Riboflavin, Tartrazin \\
\hline 26. & Propelan & Nitrogen, Propana, Dinitrogen monooksida \\
\hline 27. & Sekuestran & Natrium/Kalium glukonat, Isopropil sitrat \\
\hline
\end{tabular}

Sumber : Permenkes Nomor 033 Tahun 2012 
Ulasan ini bertujuan untuk memberikan gambaran mengenai jenis BTP berbahaya dan dampak yang ditimbulkan akibat mengkonsumsi BTP tersebut bagi kesehatan. Tulisan ini mengulas lebih mendalam pada 3 jenis bahan terlarang yang paling sering digunakan sebagai BTP yaitu formalin, boraks dan Rhodamin B.

\section{BAHAN TAMBAHAN PANGAN BERBAHAYA}

Berdasarkan Permenkes Nomor 033 Tahun 2012, pemerintah telah melarang 19 jenis bahan untuk digunakan sebagai BTP seperti disajikan pada Tabel 2. Beberapa bahan yang dilarang digunakan sebagai BTP memiliki fungsi sama seperti bahan yang diizinkan sebagai BTP antara lain sebagai pengawet (formalin, asam salisilat dan dietilpirokarbonat), pemanis (dulsin) dan memperbaiki tekstur (kalium bromat dan asam borat/boraks). Selain bahan-bahan yang tercantum dalam Tabel 1 , beberapa peraturan dari instansi terkait juga melarang penggunaan BTP lain seperti misalnya pewarna tekstil Rhodamin B, hidrogen peroksida (pemutih) dan obatobatan jenis psikotropika.

Tabel 2.

Bahan yang dilarang digunakan sebagai Bahan Tambahan Pangan

\begin{tabular}{ll}
\hline No & Bahan \\
\hline 1. & Asam borat dan senyawanya (Boric acid) \\
2. & Asam salisilat dan garamnya (Salicylic acid and its salt) \\
3. & Dietilpirokarbonat (Diethylpyrocarbonate, DEPC) \\
4. & Dulsin (Dulcin) \\
5. & Formalin (Formaldehyde) \\
6. & Kalium bromat (Potassium bromate) \\
7. & Kalium klorat (Potassium chlorate) \\
8. & Kloramfenikol (Chloramphenicol) \\
9. & Minyak nabati yang dibrominasi (Brominated vegetable oils) \\
10. & Nitrofu razon (Nitrofurazone) \\
11. & Dulkamara (Dulcamara) \\
12. & Kokain (Cocaine) \\
13. & Nitrobenzen (Nitrobenzene) \\
14. & Sinamil antranilat (Cinnamyl anthranilate) \\
15. & Dihidrosafrol (Dihydrosafrole) \\
16. & Biji tonka (Tonka bean) \\
17. & Minyak kalamus (Calamus oil) \\
18. & Minyak tansi (Tansy oil) \\
19. & Minyak sasafras (Sasafras oil) \\
\hline
\end{tabular}

Sumber : Permenkes Nomor 033 Tahun 2012

Sebagian besar bahan yang dilarang digunakan sebagai BTP (Tabel 1) tidak memberikan dampak negatif secara langsung terhadap kesehatan namun efek konsumsi bahan tersebut baru dirasakan dalam jangka panjang. Dulsin, DEPC dan Kalium Bromate merupakan senyawa karsinogen yang dalam jangka panjang dapat menyebabkan penyakit kanker. Namun 
beberapa bahan kimia akan memberikan dampak negatif secara langsung terhadap tubuh terutama apabila dikonsumsi adalam dosis berlebih misalnya asam salisilat dan formalin.

\section{FORMALIN}

Formalin adalah larutan 30-50\% gas formaldehid $\left(\mathrm{CH}_{2} \mathrm{O}\right)$ yang sering dipakai dalam pengawetan mayat, desinfektan, antiseptik serta digunakan dalam industri plastik, anti busa, kertas, karpet, tekstil, bahan konstruksi, cat dan mebel (BPOM, 2004). Walaupun dilarang, formalin banyak disalahgunakan untuk pengawet pangan seperti untuk pengawetan ikan, tahu, mie dan bakso.

Hasil pengujian sampel yang dikirimkan oleh beberapa laboratorium
Balai Pengawas Obat dan Makanan (POM) menunjukkan $51 \%$ sampel mie basah dan $22 \%$ sampel tahu mengandung formalin (Tabel 3).

Studi yang dilakukan oleh Paratmanitya \& Aprilia (2016) menunjukkan 25,5\% sampel jajanan anak Sekolah Dasar di Bantul mengandung formalin dengan proporsi terbesar berasal dari sampel jajanan jenis sosis dan diikuti sampel jajanan bakso (bulat, goreng dan tusuk). Sedangkan studi yang dilakukan Matondang dkk (2015), menunjukkan bahwa sampel ikan kembung yang diperoleh di 5 Pasar di Kota Bandung (Pasar Gedebage, Pasar Caringin, Pasar Ujung Berung, Pasar Cicaheum dan Pasar Ciroyom) terdeteksi positif mengandung formalin.

Tabel 3.

Kandungan Formalin Berdasarkan Jenis Pangan

\begin{tabular}{lccc}
\hline Jenis Pangan & Jumlah sampel & Memenuhi Syarat & Tidak Memenuhi Syarat \\
\hline Mie Basah & 103 & $50(49 \%)$ & $53(51 \%)$ \\
Tahu & 120 & $94(78 \%)$ & $26(22 \%)$ \\
Lainnya & 19 & $18(99 \%)$ & $1(1 \%)$ \\
\hline Total & 242 & $162(67 \%)$ & $80(33 \%)$ \\
\hline
\end{tabular}

Sumber : BPOM (2004)

Mengkonsumsi formalin dalam dosis yang cukup tinggi dapat menyebabkan efek langsung pada kesehatan terutama pada sistem pencernaan dan sistem syaraf dengan gejala kejang-kejang, muntah dan diare. Hal ini disebabkan sifat formalin yang sangat reaktif terhadap lapisan lendir pada saluran pernafasan dan pencernaan.

Konsumsi formalin dengan dosis lebih dari $30 \mathrm{ml}$ akan mengakibatkan kematian. Dalam jangka panjang, mengkonsumsi formalin walaupun dalam dosis yang rendah dapat mengakibatkan gangguan pada pencernaan, hati, ginjal pankreas, sistem saraf pusat, dan menyebabkan kanker (BPOM, 2004; Yuliarti, 2007).

\section{BORAKS}

Boraks $\left(\mathrm{Na}_{2} \mathrm{~B}_{4} \mathrm{O}_{7} \cdot 10 \mathrm{H}_{2} \mathrm{O}\right)$ dan asam borat $\left(\mathrm{H}_{3} \mathrm{BO}_{3}\right)$ berupa serbuk kristal putih, tidak berbau dan larut dalam air. Boraks digunakan untuk deterjen, mengurangi kesadahan, dan antiseptik 
lemah. Boraks sangat beracun dan dilarang digunakan untuk pangan. Boraks banyak disalahgunakan untuk ditambahkan pada makanan misalnya pada mie, kerupuk, makanan ringan, bakso, lontong, makaroni dengan tujuan memperbaiki warna, tekstur dan flavor (BPOM, 2004).

Hasil pengujian beberapa sampel produk pangan yang dikirimkan oleh beberapa Balai POM menunjukkan secara persentase, jenis pangan yang paling banyak mengandung boraks adalah mie basah (31\%) diikuti bakso (22\%), makanan ringan (13\%) dan kerupuk (12\%) (Tabel 4). Studi yang dilakukan oleh Suntaka, dkk (2015) pada produk bakso dari pedagang bakso keliling dan warung bakso di Bitung menunjukkan $22 \%$ sampel pedagang bakso yang diteliti menjual bakso yang mengandung formalin. Sedangkan studi yang dilakukan oleh Paratmanitya \& Aprilia (2016) menunjukkan 15,3\% sampel jajanan anak Sekolah Dasar di Bantul mengandung boraks. Secara persentase, bakso merupakan jenis makanan yang paling banyak mengandung boraks (29\%) yang berarti hampir sepertiga jajanan bakso yang dijual di lingkungan Sekolah Dasar terdeteksi mengandung boraks.

Tabel 4.

Kandungan Boraks Berdasarkan Jenis Pangan

\begin{tabular}{lccc}
\hline Jenis Pangan & Jumlah sampel & Memenuhi Syarat & Tidak Memenuhi Syarat \\
\hline Mie Basah & 117 & $81(69 \%)$ & $36(31 \%)$ \\
Bakso & 77 & $60(78 \%)$ & $17(22 \%)$ \\
Makanan Ringan & 61 & $53(87 \%)$ & $8(13 \%)$ \\
Kerupuk & 450 & $361(88 \%)$ & $49(12 \%)$ \\
Mie Kering & 315 & $314(>99 \%)$ & $1(<1 \%)$ \\
Lainnya & 242 & $224(93 \%)$ & $18(7 \%)$ \\
\hline Total & 1.222 & $1.093(89 \%)$ & $129(11 \%)$ \\
\hline
\end{tabular}

Sumber : BPOM (2004)

Mengkonsumsi makanan yang mengandung boraks baik dengan dosis rendah maupun tinggi membahayakan bagi kesehatan. Konsumsi boraks pada dosis rendah tidak menimbulkan dampak secara langsung terhadap kesehatan namun menimbulkan dampak negatif bagi kesehatan dalam jangka panjang sebab boraks akan terakumulasi di organ hati, otak dan testis (Amir dkk, 2014). Konsumsi boraks dengan dosis tinggi akan memberikan dampak langsung terhadap tubuh dengan gejala pusing, muntah, mencret dan kram perut. Bahkan boraks dapat menyebabkan kematian apabila dikonsumsi dengan dosis 5 gram oleh anak kecil dan dosis 10-20 gram oleh orang dewasa. (Nurkholidah dkk, 2012).

\section{RHODAMIN B}

Rhodamin B memiliki rumus molekul $\mathrm{C}_{28} \mathrm{H}_{31} \mathrm{~N}_{2} \mathrm{O}_{3} \mathrm{Cl}$ dan berbentuk serbuk kristal berwarna kehijauan. Apabila terlarut pada konsentrasi tinggi, Rhodamin B berwarna merah keunguan 
sedangkan apabila terlarut pada konsentrasi rendah, Rhodamin B berwarna merah terang. Rhodamin B adalah pewarna sintetis yang dibuat dari metanlinilat dan dipanel alanin. Rhodamin B tersedia di pasar untuk industri tekstil dan plastik, namun bahan ini banyak disalahgunakan pada pangan dan kosmetik. Rhodamin B sering dipakai untuk mewarnai produk pangan seperti kerupuk, terasi, makanan ringan, manisan, kembang gula, sirup, cendol, minuman ringan, saos dan lain lain. Makanan yang diberi zat pewarna Rhodamin B biasanya lebih terang atau mencolok warnanya dan memiliki rasa agak pahit (Wirasto, 2008).
Hasil pengujian beberapa sampel produk pangan yang dikirimkan oleh beberapa Balai POM menunjukkan secara persentase, jenis pangan yang paling banyak mengandung Rhodamin B yaitu kerupuk $(58 \%)$ diikuti oleh terasi (51\%) (Tabel 5). Studi yang dilakukan oleh Paratmanitya \& Aprilia (2016) menunjukkan dari 15 sampel jajanan anak yang diduga mengandung Rhodamin B, 7 sampel (46,7\%) terdeteksi mengandung Rhodamin B. Secara persentase, jenis jajanan yang positif mengandung Rhodamin B berupa jajanan Jelly. Sementara penelitian yang dilakukan oleh Dawile dkk (2013), menemukan penggunaan Rhodamin B sebagai pewarna kerupuk di Manado.

Tabel 5.

Kandungan Rhodamin B Berdasarkan Jenis Pangan

\begin{tabular}{lccc}
\hline Jenis Pangan & Jumlah sampel & Memenuhi Syarat & Tidak Memenuhi Syarat \\
\hline Kerupuk & 71 & $30(42 \%)$ & $41(58 \%)$ \\
Terasi & 80 & $29(48 \%)$ & $41(51 \%)$ \\
Makanan Ringan & 36 & $21(58 \%)$ & $15(42 \%)$ \\
Lainnya & 128 & $70(55 \%)$ & $58(45 \%)$ \\
\hline Total & 315 & $160(51 \%)$ & $155(49 \%)$ \\
\hline
\end{tabular}

Sumber : BPOM (2004)

Mengkonsumsi produk pangan yang mengandung Rhodamin B sangat berbahaya bagi kesehatan baik jangka pendek maupun jangka panjang. Mengkonsumsi Rhodamin B pada konsentrasi tertentu akan menyebabkan keracunan dengan gejala terjadinya iritasi saluran pernafasan, kulit, mata, saluran pencernaan. Dalam jangka panjang, mengkonsumsi Rhodamin B menyebabkan gangguan fungsi hati dan menyebabkan kanker (Lestina dkk, 2013).
Sebagai pewarna tekstil, Rhodamin B mengandung logam berat yang bertujuan agar efek pewarnaan pada produk tekstil menjadi lebih kuat dan awet. Namun pabila Rhodamin B dikonsumsi oleh manusia, residu logam berat akan terakumulasi dalam tubuh dan membahayakan bagi kesehatan.

Rhodamin B juga termasuk senyawa yang tidak stabil (radikal) disebabkan adanya kandungan klorin (senyawa halogen), sifat halogen adalah mudah bereaksi atau memiliki reaktivitas 
yang tinggi maka dengan demikian senyawa tersebut karena merupakan senyawa yang radikal akan berusaha mencapai kestabilan dalam tubuh dengan berikatan dengan senyawa-senyawa dalam tubuh kita sehingga pada akhirnya akan memicu kanker pada manusia (Purnamasari, 2013)

\section{KESIMPULAN DAN SARAN}

\section{Kesimpulan}

1. Melalui instansi terkait misalnya Kementrian Kesehatan dan Badan POM, pemerintah telah mengeluarkan peraturan yang mengatur penggunaan BTP termasuk memaparkan bahanbahan yang diizinkan maupun dilarang digunakan sebagai BTP.

2. Mengkonsumsi BTP berbahaya memberikan dampak negatif terhadap kesehatan manusia baik dalam jangka pendek maupun jangka panjang.

3. Penyalahgunaan BTP berbahaya khususnya formalin, boraks dan rhodamin B masih banyak terjadi di berbagai tempat di Indonesia. Oleh karena itu perlu tindakan yang serius untuk mengatasi penyalahgunaan tersebut.

\section{Saran}

1. Perlunya dilakukan sosialisasi melalui berbagai media mengenai bahaya penggunaan BTP terlarang, cara mendeteksinya serta alternatif BTP alami dan aman untuk dikonsumsi.

2. Pengawasan dan penegakan hukum terhadap penyalahgunaan bahan yang dilarang sebagai BTP harus terus dilakukan baik terhadap toko-toko bahan kimia, industri pangan dan toko-toko makanan.

3. Perlunya dilakukan penelitian terhadap sampel pangan yang dijual di lokasi-lokasi yang rentan terjadi penyalahgunaan BTP terlarang misalnya di sekolah dan pasar tradisional.

\section{DAFTAR PUSTAKA}

Amir, S., Sirajuddin, S., Zakaria. (2014). Analisis Kandungan Boraks Pada Pangan Jajanan Anak di SDN Kompleks Lariangbangi Kota Makassar. Skripsi. Program Studi Ilmu Gizi Fakultas Kesehatan Masyarakat. Makassar : Universitas Hasanuddin.

Badan Pengawas Obat dan Makanan Republik Indonesia. (2004). Bahan Tambahan Ilegal - Boraks, Formalin dan Rhodamin B. Badan POM RI bekerjasama dengan Balai Besar Industri Agro, Departemen Pertanian, Institut Pertanian Bogor dan World Health Organization.

Dawile, S., Fatimawali., Wehantouw, F. (2013). Analisis Zat Pewarna Rhodamin B Pada Kerupuk Yang Beredar di Kota Manado. PHARMACON. Vol 2 (3) : 86-90.

Gartini, T. (2009). Monitoring dan Verifikasi Profil Keamanan Pangan Jajanan Anak Sekolah (PJAS) Nasional Tahun 2008. Prosiding Lokakarya Jejaring Intelijen Pangan (hal. 1-10). 
Jakarta: Badan Pengawas Obat dan Makanan Republik Indonesia.

Lestari, S. T. (2009). Studi Kadungan Boraks Pada Kerupuk Gendar Yang Dijual di Pasar Mranggen Kabupaten Demak Tahun 2008. Karya Tulis Ilmiah. Jurusan Kesehatan Lingkungan. Semarang : Politeknik Kesehatan.

Lestina, I. B., Chahaya, I., Marsaulina, I. (2013). Analisis Kandungan Rhodamin B dan Pemanis Buatan (Sakarin) Pada Buah Semangka (Citrullus Lanatus) Yang Dijual di Pasar Tradisional dan Pasar Moderen Kota Medan Tahun 2013. Lingkungan \& Kesehatan Kerja. Vol 2(3) : 1-7.

Matondang, R. A., Rochima E., Kurniawati, N. (2015). Studi Kandungan Formalin dan Zat Pemutih Pada Ikan asin di Beberapa Pasar Kota Bandung. Jurnal Perikanan Kelautan. Vol 6 No 2(1) : 70-77.

Nurkholidah, M., Ilza \& Jose, C. (2012). Analisis Kandu) ngan Boraks pada Jajanan Bakso Tusuk di Sekolah Dasar di Kecamatan Bangkinang Kabupaten Kampar. Jurnal Ilmu Lingkungan. Vol 6 (2) : 134-145.

Paratmanitya, Y., Aprilia, V. (2016). Kandungan Bahan Tambahan Pangan Berbahaya Pada Makanan Jajanan Anak Sekolah Dasar di Kabupaten Bantul. Jurnal Gizi dan Dietetik Indonesia. Vol 4(1) : 4955.
Purnamasari, D. S. (2013). Pengaruh Rhodamine B Peroral Dosis Bertingkat Selama 12 Minggu Terhadap Gambaran Histomorfometri Limpa: Studi Pada Diameter Folikel Pulpa Putih, Diameter dan Jarak Zona Marginalis Limpa Tikus Wistar. Karya Tulis Ilmiah. Program Pendidikan Sarjana Kedokteran. Semarang : Fakultas Kedokteran Universitas Diponegoro.

Saparinto, C. Hidayati, D. (2006). Bahan Tambahan Pangan. Yogyakarta: Kanisius.

Suntaka, D. F., Joseph, W. B., Sondakh, R. C. (2015). Analisis Kandungan Formalin dan Boraks Pada Bakso Yang Disajikan Kios Bakso Permanen Pada Beberapa Tempat di Kota Bitung Tahun 2014. KESMAS : 39-45.

Wirasto. (2008). Analisis Rhodamin B dan Metanil Yellow dalam Minuman Jajanan Anak SD di Kecamatan Laweyan Kotamadya Surakarta dengan Metode Kromatografi Lapis Tipis. Skripsi. Fakultas Farmasi. Surakarta : Universitas Muhammadiyah Surakarta.

Yuliarti, N. (2007). Awas! Bahaya di Balik Lezatnya Makanan. Yogyakarta: Penerbit ANDI.

Peraturan Menteri Kesehatan Republik Indonesia Nomor 033 Tahun 2012 tentang Bahan Tambahan Pangan. 
Peraturan Pemerintah Republik Indonesia

Nomor 28 Tahun 2004 tentang

Keamanan, Mutu dan Gizi

Pangan.

Undang-Undang Republik Indonesia

Nomor 18 Tahun 2012 tentang Pangan.

\section{BIODATA PENULIS}

Jatmiko Wahyudi, lahir 5 Oktober 1979

di kota Pati, Jawa Tengah. Gelar Sarjana
Teknik (ST) diperoleh dari Jurusan Teknik Kimia, Universitas Sebelas Maret Surakarta. Pendidikan S2 diperoleh melalui program dobel degree di jurusan Ilmu Lingkungan Universitas Padjadjaran, Bandung dan Jurusan Environmental and Energy Management, The University of Twente, Belanda. Saat ini bekerja sebagai peneliti di Badan Perencanaan Pembangunan Daerah (BAPPEDA) Kabupaten Pati. 